\title{
PREPARATION OF AMORPHOUS CALCIUM-MAGNESIUM PHOSPHATES AT pH 7 AND CHARACTERIZATION BY X-RAY ABSORPTION AND FOURIER TRANSFORM INFRARED SPECTROSCOPY
}

\section{HOLT}

Hannah Research Institute, Ayr KA6 5HL, Scotland, UK

\section{M.J.J.M. VAN KEMENADE}

Van 't Hoff Laboratory, Transitorium 3, Padualaan 8, $3584 \mathrm{CH}$ Utrecht, The Netherlands

\section{J.E. HARRIES}

SERC Daresbury Laboratory, Warrington WA4 $4 A D, U K$

\section{L.S. NELSON *}

Hannah Research Institute, Ayr KA6 5HL, Scotland, UK

\section{R.T. BAILEY}

Department of Pure and Applied Chemistry, University of Strathclyde, Glasgow GI 1XL, Scotland, UK

\section{D.W.L. HUKINS}

Department of Medical Biophysics, University of Manchester, Manchester MI3 9PT, UK

\section{S.S. HASNAIN}

SERC Daresbury Laboratory, Warrington WA4 4AD, UK

and

\section{P.L. DE BRUYN}

Van 't Hoff Laboratory, Transitorium 3, Pandualaan 8, 3584 CH Utrecht, The Netherlands

Received 8 March 1988; manuscript received in final form 7 May 1988

\begin{abstract}
Amorphous calcium-magnesium phosphates were prepared by precipitation from moderately supersaturated aqueous solutions at $\mathrm{pH}$ 7. Chemical analysis of the samples by ion chromatography showed that up to about $50 \%$ of the phosphate ions were protonated, the proportion increasing with the magnesium to calcium ion activity ratio in the solution. When left it contact with the supernatant, the amorphous precipitates matured to form the crystalline calcium phosphate brushite $\left(\mathrm{CaHPO}_{4} \cdot 2 \mathrm{H}_{2} \mathrm{O}\right)$. The amorphous phases were characterized by $\mathrm{X}$-ray absorption spectroscopy and by Fourier transform infrared spectroscopy and their properties compared with those of a basic amorphous tricalcium phosphate precipitated at $\mathrm{pH} 10$. The $\mathrm{X}$-ray absorption spectra near the $\mathrm{K}$ edge of calcium were very similar for all samples but there were differences in the infrared spectra between the basic and the more acidic salts. In the phosphate stretching region, the main band of the more acidic materials occurred at higher wavenumber and was broader. Also there was a broad band of medium intensity at about $890 \mathrm{~cm}^{-1}$ whereas there was virtually no absorption band in this region in the spectrum of the amorphous tricalcium phosphate. The acidic amorphous calcium phosphates may be useful as model compounds in describing some complex biological calcium phosphates that form near neutral $\mathrm{pH}$.
\end{abstract}

* Also at Department of Medical Biophysics, University of Manchester, Manchester M13 9PT, UK.

0022-0248/88/\$03.50 C Elsevier Science Publishers B.V.

(North-Holland Physics Publishing Division) 


\section{Introduction}

Precipitation of calcium phosphate from a moderately or highly supersaturated solution, at or above neutral $\mathrm{pH}$, tends to produce an initial amorphous phase, the so-called amorphous calcium phosphate (ACP). Subsequently, a more stable crystalline phase is formed such as brushite $\left(\mathrm{CaHPO}_{4} \cdot 2 \mathrm{H}_{2} \mathrm{O}\right)$, octacalcium phosphate (OCP, $\left.\mathrm{Ca}_{8} \mathrm{H}_{2}\left(\mathrm{PO}_{4}\right)_{6} \cdot 5 \mathrm{H}_{2} \mathrm{O}\right)$, or an apatite such as hydroxyapatite ( $\left.\mathrm{HA}, \mathrm{Ca}_{10}(\mathrm{OH})\left(\mathrm{PO}_{4}\right)_{6}\right)$. The nature of the amorphous phase has been the subject of very many investigations. For example Termine and Eanes [1] showed that its chemical composition was variable, depending on solution $\mathrm{pH}$, such that $\mathrm{Ca} / \mathrm{P}$ decreased and the proportion of the phosphate as $\mathrm{HPO}_{4}^{2-}$ rather than $\mathrm{PO}_{4}^{3-}$ ions increased with decreasing $\mathrm{pH}$. Below $\mathrm{pH}$ 6.6, no amorphous phase was detected; brushite appeared to precipitate directly from solution. At $\mathrm{pH} 6.6$, $33 \%$ of the phosphate was in the form of $\mathrm{HPO}_{4}^{2-}$ ions and $\mathrm{Ca} / \mathrm{P}$ was 1.18 . At higher $\mathrm{pH}, \mathrm{Ca} / \mathrm{P}$ approached the value for a tricalcium phosphate of 1.5 , particularly when the precipitate was washed, since the $\mathrm{HPO}_{4}^{2-}$ ions were preferentially lost and $\mathrm{Ca} / \mathrm{P}$ in the precipitate rose. At $\mathrm{pH} 7.4$, about $10 \%$ of the phosphate was $\mathrm{HPO}_{4}^{2-}$ ions as judged from the form of the solubility product controlling precipitation [2], and at higher $\mathrm{pH}$ the composition became more complex as $\mathrm{OH}^{-}$ions may have been incorporated [3]. Likewise, in precipitations from solutions containing magnesium salts, $\mathrm{Mg}^{2+}$ may be incorporated in the ACP [4]. Thus, in different circumstances a range of precipitates can be produced to which the generic name ACP is applied $[5,6]$ but the corollary is that the detection of an amorphous product provides little information about chemical composition.

The amorphous tricalcium phosphate is the most thoroughly characterized form of ACP. In one model of its structure it is described as being formed from $\mathrm{Ca}_{9}\left(\mathrm{PO}_{4}\right)_{6}$ clusters; a similar cluster can be identified in the unit cell of apatites $[7,8]$. In a different approach, Harries et al. [9] have described the average short range environment of calcium ions in the ACP using a shell model derived from the hydroxyapatite lattice. Only small adjustments in structural parameters out to a max- imum distance of $0.307 \mathrm{~nm}$ from the calcium ions were required to describe the $\mathrm{X}$-ray absorption spectrum of the amorphous phase near the $\mathrm{K}$ edge of calcium.

It has been proposed that there is an amorphous dicalcium phosphate [10] but no evidence of such a phase has been reported in simple calcium phosphate systems. In milk, however, there is an amorphous calcium phosphate complexed to casein phosphoproteins $[11,12]$ which has a solubility and chemical composition that suggests that it is an acidic ACP [12]. In the work of Termine and Eanes [1], ACPs produced at $\mathrm{pH} 7$ are appreciably acidic and a similar phase has been produced from a salt solution simulating intracellular fluid [13]. Thus, the basic ACP may not be the most appropriate model for understanding the structure and formation of biological calcium phosphates formed near neutral $\mathrm{pH}$.

In this paper we describe the preparation, chemical composition and some physical properties of four amorphous calcium-magnesium phosphates formed at $\mathrm{pH}$ 7.0. Magnesium was included in the precipitating solutions to make them more similar to physiological fluids. We also describe the maturation of these ACPs to form brushite. The usefulness of Fourier transform infrared spectroscopy to distinguish between the acidic and basic ACPs is demonstrated and we show that the short range structure around the calcium ions in these acidic ACPs is similar to that in the basic ACP.

\section{Methods}

Four amorphous calcium-magnesium phosphates were prepared at $\mathrm{pH} 7$. Three of these, designated $\mathrm{H} 1-\mathrm{H} 3$, were prepared at the Hannah Research Institute, Ayr, and contained different proportions of magnesium. The fourth, T1, was prepared at the Van 't Hoff Laboratorium, Utrecht, and, in addition to physical and chemical characterization, was used in a study of the maturation of the ACP.

\subsection{Preparation of samples $\mathrm{H} 1, \mathrm{H} 2$ and $\mathrm{H} 3$}

These were prepared at room temperature by mixing together $500 \mathrm{ml}$ of each of solutions $\mathrm{A}$ and 
B. Then, with rapid stirring, the $\mathrm{pH}$ was raised to 7.0 by addition of $0.4 \mathrm{M} \mathrm{NaOH}$ and the gelatinous precipitate allowed to form while maintaining the $\mathrm{pH}$ constant at 7.0. Solution A comprised $100 \mathrm{mM}$ $\mathrm{NaH}_{2} \mathrm{PO}_{4}$ and $100 \mathrm{mM} \mathrm{Na}_{2} \mathrm{HPO}_{4}$, while solution B contained $4 \mathrm{mM} \mathrm{CaCl} 2,135 \mathrm{mM} \mathrm{NaCl}$ and a $\mathrm{MgCl}_{2}$ concentration of either $6 \mathrm{mM}, 10 \mathrm{mM}$ or $14 \mathrm{mM}$ to provide sample $\mathrm{H} 1, \mathrm{H} 2$ or $\mathrm{H} 3$, respectively. In all the mixtures the degree of supersaturation with respect to brushite (i.e. the ion activity product divided by the intrinsic solubility product), prior to the onset of precipitation, was calculated to be 6.7 at $\mathrm{pH} 7$ [14]. The precipitate was separated by filtration through a Sartorius membrane of porosity $0.45 \mu \mathrm{m}$ some $10-13 \mathrm{~min}$ after mixing. It was frozen quickly by laying the filtration membrane on a steel block cooked to $-15^{\circ} \mathrm{C}$, freeze dried and stored over silica gel.

\subsection{Preparation of sample $T I$}

This sample was prepared in a reaction vessel specially designed for studies on the kinetics of nucleation and crystal growth $[15,16]$. Solutions of $\mathrm{KH}_{2} \mathrm{PO}_{4}, \mathrm{Ca}\left(\mathrm{NO}_{3}\right)_{2}$ and $\mathrm{Mg}\left(\mathrm{NO}_{3}\right)_{2}$ were mixed together at a pH of about 4.5 to yield final concentrations of $10 \mathrm{mM}$ phosphate, $5 \mathrm{mM}$ calcium and $5 \mathrm{mM}$ magnesium. In order to maintain an approximately constant ionic strength during precipitation, $0.15 \mathrm{M} \mathrm{KNO}_{3}$ was added as a background electrolyte. Precipitation of calcium phosphate was initiated by raising the $\mathrm{pH}$ by addition of $0.5 \mathrm{M} \mathrm{KOH}$ such that during the formation of the initial gelatinous precipitate, the $\mathrm{pH}$ was maintained constant at 7.0. At this $\mathrm{pH}$ the calculated degree of supersaturation was 3.5 , approximately half that in the other solutions. The addition of $\mathrm{KOH}$ was most rapid in the earliest stages of addition and slowed continuously thereafter, which is characteristic of diffusion limited growth of the initial precipitate. Continuous growth, often limited by monomer diffusion, is generally observed in the formation of amorphous precursor phases with relatively high solubilities and as a result low surface energies. After about $7 \mathrm{~h}$ the $\mathrm{pH}$ began to rise above 7 and brushite could then be detected in the precipitate. Up to that time, the composition and measured physical properties of the amorphous phase were constant. In separate experiments, samples were removed at various times for up to $44 \mathrm{~h}$ after mixing. The initial and matured precipitates were isolated by filtration through a membrane of $0.45 \mu \mathrm{m}$ porosity, immediately dried in vacuo and stored in a desiccator over silica gel.

\subsection{Preparation of an amorphous tricalcium phos- phate}

The preparation of this sample at $\mathrm{pH} 10$ is described by Harries et al. [9]. A series of poorly crystalline apatite-like samples was obtained by allowing this amorphous phase to remain in contact with the solution for periods of up to $120 \mathrm{~h}$. These samples, together with the partially matured samples derived from sample $\mathrm{Tl}$ were used to calibrate the oxalate titration method (see below).

\subsection{Determination of the chemical composition of the samples}

Particular attention was paid to the determination of the chemical composition of the samples in order to demonstrate that they differ from the conventionally recognised ACP which has a stoichiometry approximating a hydrated tricalcium phosphate.

\subsubsection{Analysis by ion chromatography}

The calcium phosphate samples were dissolved in a slight molar excess of either $\mathrm{HCl}$ or $\mathrm{HNO}_{3}$, depending on whether $\mathrm{Cl}^{-}$or $\mathrm{NO}_{3}^{-}$was to be determined in the salt. Ion concentrations were then determined by ion chromatography, as previously described [17], using a Dionex QIC chromatograph. This technique detects all the major ionic constituents (table 1) apart from $\mathrm{H}^{+}$and $\mathrm{OH}^{-}$. However, the difference between titratable protons and hydroxide ions can be determined by a charge balance calculation. Assuming $\mathrm{HPO}_{4}^{2-}$ and $\mathrm{OH}^{-}$ions are present:

$$
\begin{aligned}
& (\mathrm{H}-\mathrm{OH}) \\
& \quad=3-\left(2 \mathrm{Ca}+2 \mathrm{Mg}+\mathrm{Na}+\mathrm{K}-\mathrm{NO}_{3}-\mathrm{Cl}\right) / \mathrm{P},
\end{aligned}
$$

where the chemical symbols on the right hand side denote the molar amount per unit weight, $H$ is the 
Table 1

Composition of amorphous calcium-magnesium phosphates

\begin{tabular}{|c|c|c|c|c|}
\hline & $\mathrm{T} 1^{\text {a) }}$ & $\mathrm{H} 1$ & $\mathrm{H} 2$ & H3 \\
\hline$\overline{\mathrm{Ca}^{2+}(\mathrm{mmol} / \mathrm{g})}$ & $5.20(0.14)$ & 4.96 & 4.52 & 4.55 \\
\hline $\mathrm{Mg}^{2+}(\mathrm{mmol} / \mathrm{g})$ & $1.15 \quad(0.04)$ & 1.12 & 1.41 & 1.72 \\
\hline $\mathrm{K}^{+}(\mathrm{mmol} / \mathrm{g})$ & $1.45(0.20)$ & - & - & - \\
\hline $\mathrm{Na}^{+}(\mathrm{mmol} / \mathrm{g})$ & - & 1.81 & 1.80 & 1.74 \\
\hline$P_{i}(\mathrm{mmol} / \mathrm{g})$ & $4.91 \quad(0.14)$ & 5.12 & 5.03 & 5.43 \\
\hline $\mathrm{NO}_{3}^{-}(\mathrm{mmol} / \mathrm{g})$ & $1.22(0.24)$ & - & - & - \\
\hline $\mathrm{Cl}^{-}(\mathrm{mmol} / \mathrm{g})$ & - & 0.329 & 0.488 & 0.395 \\
\hline$(\mathrm{H}-\mathrm{OH})^{\mathrm{b})}$ & $0.363(0.020)$ & 0.335 & 0.381 & 0.443 \\
\hline$(H-O H)^{\mathrm{c})}$ & $0.426(0.021)$ & 0.330 & 0.465 & 0.548 \\
\hline $\mathrm{H}_{2} \mathrm{O}(\% \mathrm{w} / \mathrm{w})$ & $16.3 \quad(1.5)$ & 23.4 & 23.9 & 20.5 \\
\hline $\mathrm{Ca} / \mathrm{P}_{\mathrm{i}}$ & $1.06(0.10)$ & 0.97 & 0.90 & 0.84 \\
\hline$(\mathrm{Ca}+\mathrm{Mg}) / \mathrm{P}_{\mathrm{i}}$ & $1.31 \quad(0.03)$ & 1.19 & 1.18 & 1.15 \\
\hline
\end{tabular}

a) Mean of 5 preparations with standard deviation.

b) By charge balance.

c) By oxalate titration.

mole fraction of phosphate present as $\mathrm{HPO}_{4}^{2-}$ ions and $\mathrm{OH}$ is the number of mol of $\mathrm{OH}^{-}$ions per mol phosphate in the sample. In the absence of a significant number of $\mathrm{OH}^{-}$ions, $(\mathrm{H}-\mathrm{OH})$ is then the average degree of protonation of the phosphate groups. Finally, the water content of the samples was determined by difference after computing the sum of the weight fractions of the ionic species.

\subsubsection{Oxalate titration method}

An alternative and virtually independent method of determining $(\mathrm{H}-\mathrm{OH})$ was sought because of the importance of this quantity in distinguishing acidic from basic amorphous calcium phosphates. The oxalate titration method of Pyne and Ryan [18] was considerably adapted as described below. The principle of the method is that a calcium phosphate salt is suspended in a phosphate-buffered potassium oxalate solution at a $\mathrm{pH}$ in the range 6.0-7.0. Initially there are titratable protons on the phosphate ions in the buffer: $\left[\mathrm{HPO}_{4}^{2-}\right]_{\mathrm{s}}+2\left[\mathrm{H}_{2} \mathrm{PO}_{4}^{-}\right]_{s}$ and titratable protons and hydroxide ions in the calcium phosphate salt, for example $\left[\mathrm{HPO}_{4}^{2-}\right]_{\mathrm{c}}+\left[\mathrm{OH}^{-}\right]_{c}$. The difference between the titratable protons and hydroxide ions in the initial state is then:

$\left(\frac{2+R}{1+R}\right)[\mathrm{P}]_{\mathrm{s}}+\left[\mathrm{HPO}_{4}^{2-}\right]_{\mathrm{c}}-\left[\mathrm{OH}^{-}\right]_{\mathrm{c}}$, where $[\mathrm{P}]_{\mathrm{s}}=\left[\mathrm{HPO}_{4}^{2-}\right]_{\mathrm{s}}+\left[\mathrm{H}_{2} \mathrm{PO}_{4}^{-}\right]_{\mathrm{s}}$ is the total buffer phosphate concentration, $R=$ $\left[\mathrm{HPO}_{4}^{2-}\right]_{\mathrm{s}} /\left[\mathrm{H}_{2} \mathrm{PO}_{4}^{-}\right]_{\mathrm{s}}=K_{\mathrm{a}} /\left[\mathrm{H}^{+}\right]_{\mathrm{s}}$ and $K_{\mathrm{a}}$ is the appropriate acid dissociation constant for the phosphate ions. The calcium phosphate dissolves and calcium oxalate is precipitated. To maintain $\mathrm{pH}$ at its initial value, $m$ mol of $\mathrm{HCl}$ are added per mol of phosphorus in the calcium phosphate salt. In the final state, therefore, the titratable protons are given by:

$\left(\frac{2+R}{1+R}\right)[\mathrm{P}]_{\mathrm{s}}+[\mathrm{P}]_{\mathrm{c}}+m[\mathrm{P}]_{\mathrm{c}}$

Subtraction of (1) from (2) and rearrangement gives:

$(H-O H)=(2+R) /(1+R)-m$.

Approximately $20 \mathrm{mg}$ of sample was accurately weighed into a screw-cap bottle of $25 \mathrm{ml}$ capacity and $20 \mathrm{ml}$ of a buffer solution was added, of composition $100 \mathrm{mM} \mathrm{NaH} \mathrm{PO}_{4}$ plus $20 \mathrm{mM}$ $(\mathrm{COOK})_{2}$, with $\mathrm{pH}$ adjusted to a value between 6.0 and 7.0. The suspension was stirred on a flat-bed magnetic stirrer overnight and the $\mathrm{pH}$ returned to its original value by known additions of standard $50 \mathrm{mM} \mathrm{HCl}$. Further additions of standard acid were made at $24 \mathrm{~h}$ intervals until the pH was constant and no more calcium oxalate precipitated. With either brushite or the anhydrous dicalcium phosphate monetite, the reaction was complete in $48 \mathrm{~h}$ but with the less soluble basic salts up to a further $48 \mathrm{~h}$ was required.

\subsubsection{Comparison of methods for determining ( $\mathrm{H}-\mathrm{OH})$}

The validity of this method was tested in two ways. First the titration of pure brushite and monetite was carried out and $\mathrm{p} K_{\mathrm{a}}$ computed assuming $(H-O H)=1$. This was repeated at five buffer $\mathrm{pH}$ values in the range 6.00 to 7.00 , giving $\mathrm{p} K_{\mathrm{a}}=6.97 \pm 0.04$ irrespective of which salt was used. The second test was a comparison of the method with the charge balance calculation on 21 samples of calcium phosphate prepared by partial maturation of ACPs into either brushite or poorly crystalline hydroxyapatite. The mean difference (charge balance-oxalate titration) was small at 


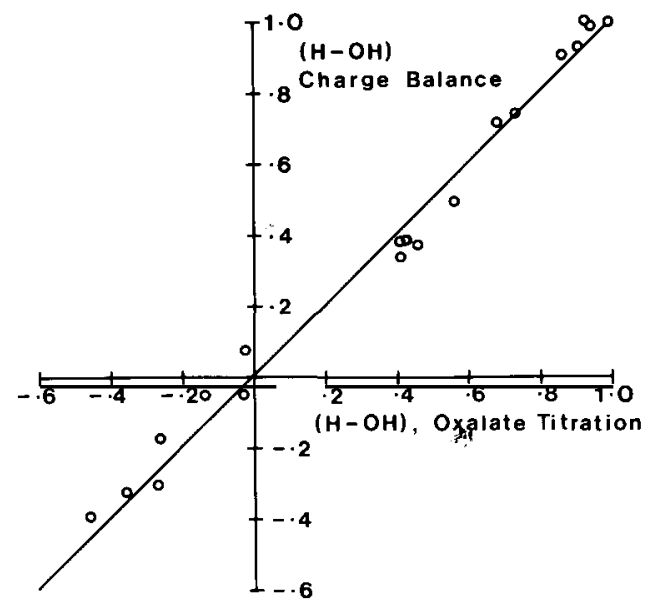

Fig. 1. Comparison of two methods of determining $(\mathrm{H}-\mathrm{OH})$, the difference between the number of protons and hydroxide ions per atom of phosphorus in calcium phosphates prepared at $\mathrm{pH} 7$ (upper quadrant) and at $\mathrm{pH} 10$.

\pm 0.02 and the root mean square difference was 0.072 . Linear regression of charge balance on oxalate titration results gave a line passing close to the origin $(0,0.022)$ with a slope near unity $(1.00$ \pm 0.22 ) and a Pearson correlation coefficient of 0.989 (fig. 1).

\section{5. $X$-ray powder diffraction}

Diffraction patterns were recorded with a Debye-Scherrer camera using nickel filtered copper $\mathrm{K} \alpha$ radiation and an exposure time of $2.5 \mathrm{~h}$, as described by Cox et al. [19].

\subsection{Scanning electron microscopy}

Micrographs of solid samples collected at various times during the maturation of sample T1 were taken using a Camscan stereoscan electron microscope. For morphological studies the samples were gold coated. A Link X-ray microanalysis system (type number 55S) was used in conjunction with the electron microscope for direct surface chemical analysis of carbon coated samples. Relative contents of $\mathrm{Ca}, \mathrm{Mg}, \mathrm{K}$ and $\mathrm{P}$ were determined on selected fields of amorphous or crystalline material and compared with the results from ion chromatography.

\subsection{X-ray absorption spectroscopy}

Spectra were measured above the $\mathrm{K}$ absorption edge of calcium at the Synchrotron Radiation Source, Daresbury Laboratory, operating at $2 \mathrm{GeV}$ with a beam current of about $90 \mathrm{~mA}$, as described previously $[9,20]$. Extended X-ray absorption fine structure (EXAFS) spectra, observed as modulations in the X-ray absorption coefficient, were obtained by removal of the smoothly varying background absorption of the samples as described elsewhere $[9,20]$. These spectra were plotted as a function of photoelectron wavenumber, $k$, where

$k^{2}=\frac{2 m^{\prime}}{\hbar^{2}}\left(E-E_{0}\right)$

$m^{\prime}$ is the mass of the electron, $\hbar$ is Planck's constant divided by $2 \pi, E$ is the photon energy and $E_{0}$ the energy of the $\mathrm{K}$ absorption edge of calcium $(4.038 \mathrm{keV})$. Each spectrum $\chi(k)$ was multiplied by $k^{3}$ to enhance its features at high $k$ values and was Fourier transformed as previously described $[9,20]$. The result approximates the radial distribution of atoms surrounding the absorbing calcium ion [21-23].

Theoretical EXAFS spectra were calculated using the exact spherical wave theory appropriate to a powdered sample [24]. It has been shown that the EXAFS spectra of crystalline hydroxyapatite [9], brushite and monetite [20] can each be closely fitted using models based on the average environment of calcium ions in these minerals, comprising a series of concentric shells of atoms. Each shell is characterized by an occupation number, $N$, radius $r$ and Debye-Waller factor $2 \sigma^{2}$. In general the shell structure of the model is very similar to that expected from the crystal structure, but multiple scattering effects have to be taken into account $[9,20,25]$. For example, in the brushite structure, phosphorus atoms at $r=0.37 \mathrm{~nm}$ and $\mathrm{O}$ atoms at $r \simeq 0.58 \mathrm{~nm}$ lie in the shadow of $O$ atoms at $r=0.24 \mathrm{~nm}$; a significant amount of forward scatter by the inner shell is rescattered by the outer $P$ and $O$ shells to appreciably modify the EXAFS spectrum from that which would result from single scattering only. 
The shell model for hydroxyapatite [25] was used to interpret the EXAFS spectrum of the amorphous tricalcium phosphate prepared at $\mathrm{pH}$ 10 [20]. Only the three innermost shells with slightly different radii and Debye-Waller factors were required to describe the spectrum of the amorphous material; no effects of multiple scattering were apparent. In order to fit the EXAFS spectrum of more acidic amorphous calcium phosphates prepared at $\mathrm{pH} 7$, we have used the shell model for hydroxyapatite. However, since the amorphous materials are intermediate in acidity between tri- and di-calcium phosphates, we have also employed the shell model for brushite as a starting point.

\subsection{Fourier transform infrared spectroscopy}

Spectra were measured using $\mathrm{KBr}$ disks of high and uniform optical transparency at sample concentrations of about $0.3 \% \mathrm{w} / \mathrm{w}$. The precise concentration was determined subsequently by chemical analysis of the disk for phosphate. The spectrometer used was a Nicolet 20 SX B model operating at a resolution of $2 \mathrm{~cm}^{-1}$ over the range $4000-250 \mathrm{~cm}^{-1}$.

To enhance features of the infrared spectra, Fourier self-deconvolution was employed [26], as implemented in the FSD software package from the instrument manufacturer. In applying this method it is assumed that an envelope curve comprises discrete but overlapping bands, Lorentzian in shape, and with a constant peak width over the envelope. The choice of peak width for self-deconvolution is therefore often a compromise. This technique was used to enhance features in the phosphate stretching region $\left(1300-850 \mathrm{~cm}^{-1}\right)$ where there are a number of overlapping modes arising from $\mathrm{PO}_{4}^{3-}$ and $\mathrm{HPO}_{4}^{2-}$ species. In practice the spectrum from about $1300 \mathrm{~cm}^{-1}$ to about $700 \mathrm{~cm}^{-1}$ was Fourier transformed and the interferogram $I(x)$ multiplied by an exponential function, $\exp (2 \pi \sigma|x|)$, where $\sigma$ is the peak width of the Lorentzian profile against which the spectrum "is deconvolved. The efficiency of the operation is given by the parameter $K$, which is the ratio of the peak width before self-deconvolution to that after [26]. This procedure increases spectral noise and introduces side lobes [26], so an apodization function is applied to the interferogram; systematic investigation showed that for these spectra the cosine apodization option in the program produced the most satisfactory results. Increasing the value of $K$ or using a peak width that was either too large or too small tended to introduce features in the deconvolved spectrum that had no discernible origin in the recorded spectrum. To avoid artefacts, deconvolution was employed conservatively to identify the positions of bands giving rise to features that were already apparent in the original spectrum.

\section{Results and discussion}

\subsection{Chemical composition of the amorphous calcium-magnesium phosphates}

The chemical compositions of the four samples are summarized in table 1 . The two, virtually independent, methods of determining $(\mathrm{H}-\mathrm{OH})$ are in agreement in demonstrating that an appreciable fraction of the phosphate groups are protonated. Titration methods such as the oxalate method or the acid/base titration of Meyer [3] or the charge balance calculation do not determine the separate $\mathrm{H}^{+}$and $\mathrm{OH}^{-}$components but only their difference. The infrared spectroscopic evidence does not eliminate the possibility of a significant content of $\mathrm{OH}^{-}$in the amorphous structure so it is an assumption that $\mathrm{OH}^{-}$in the samples can be neglected. If the $\mathrm{OH}^{-}$content is not negligible, then the titration methods or the charge balance calculation yield a value for $(\mathrm{H}-\mathrm{OH})$ that is obviously lower than the proportion of protonated phosphate groups. Making the assumption of no $\mathrm{OH}^{-}$ions in the samples and that the only protonated phosphate ions are $\mathrm{HPO}_{4}^{2-}$, we calculate that between about a third and a half of the phosphate groups are protonated.

The $\left[\mathrm{Mg}^{2+}\right] /\left[\mathrm{Ca}^{2+}\right]$ ratio in the solution appears to affect the $\mathrm{HPO}_{4}^{2-}$ content of the amorphous precipitates. Using results for the four samples $\mathrm{H} 1-\mathrm{H} 3$ and $\mathrm{Tl}$, a positive, linear, relation was found between $(\mathrm{H}-\mathrm{OH})$ and $\left[\mathrm{Mg}^{2+}\right] /\left[\mathrm{Ca}^{2+}\right]$ with a slope of +0.054 and intercept at $\left[\mathrm{Mg}^{2+}\right] /$ 
$\left[\mathrm{Ca}^{2+}\right]=0$ of 0.25 . The latter compares closely with the value of 0.27 for the fraction of the phosphate in the form of $\mathrm{HPO}_{4}^{2-}$ in the ACP of Termine and Eanes [1], prepared at $\mathrm{pH} 7$ in the absence of magnesium ions. This close agreement of results also supports the assumption that there are few hydroxide ions in these samples since Termine and Eanes [1] determined the $\mathrm{HPO}_{4}^{2-}$ content by pyrolysis to form pyrophosphate, a reaction which should be independent of the presence of hydroxide ions.

\subsection{X-ray powder diffraction and scanning electron microscopy}

None of the samples listed in table 1 gave $\mathrm{X}$-ray powder diffraction lines corresponding to crystalline forms of calcium or magnesium phosphates; a few faint lines were visible in the powder pattern of sample $\mathrm{T} 1$ which correspond to $\mathrm{KNO}_{3}$ formed by the background electrolyte on drying. Likewise, powder patterns of $\mathrm{H} 1-\mathrm{H} 3$ also showed faint lines due to the background electrolyte $\mathrm{NaCl}$. Washing of the precipitates to remove background electrolyte was avoided because this alters the precipitate calcium and phosphate composition [1].

An electron micrograph of sample $\mathrm{T} 1$ shows that there are two different phases present (fig. 2a). In the figure, the principal phase appears as an irregular block but lying on its surface are tablets of crystalline material. Examination of the tablets by X-ray microanalysis revealed potassium ions as the main detected component with no magnesium or phosphorus and only traces of calcium. It is likely, therefore, that the crystals are the $\mathrm{KNO}_{3}$ detected by $\mathrm{X}$-ray powder diffraction. When fields containing no tablets were examined by X-ray microanalysis, the calculated ratios of calcium, magnesium and phosphorus were in good agreement with the chemical analysis by ion chromatography, and there was very little potassium present.

\subsection{EXAFS spectra}

The spectrum of sample T1, weighted by $k^{3}$, and the modulus of its Fourier Transform are
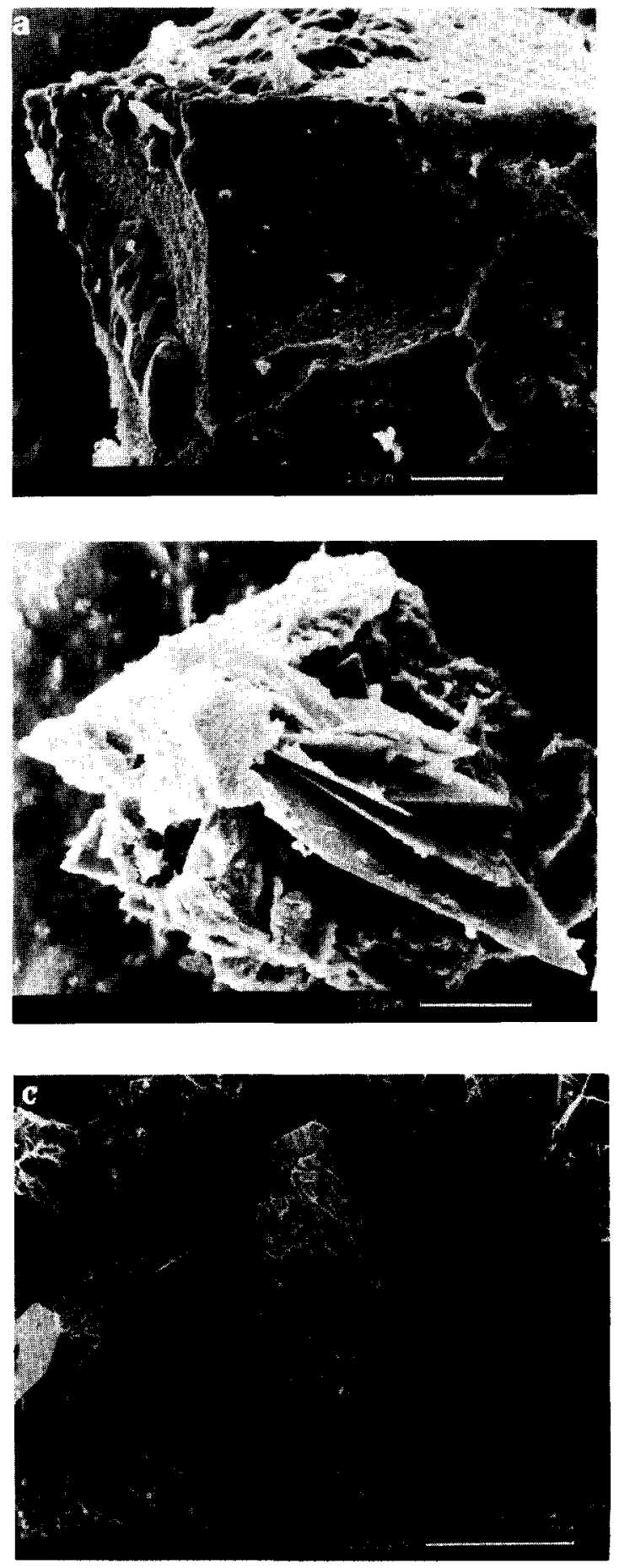

Fig. 2. Scanning electron micrographs of: (a) sample T1; (b) sample T1 after $8.3 \mathrm{~h}$; (c) sample T1 after $39 \mathrm{~h}$. 

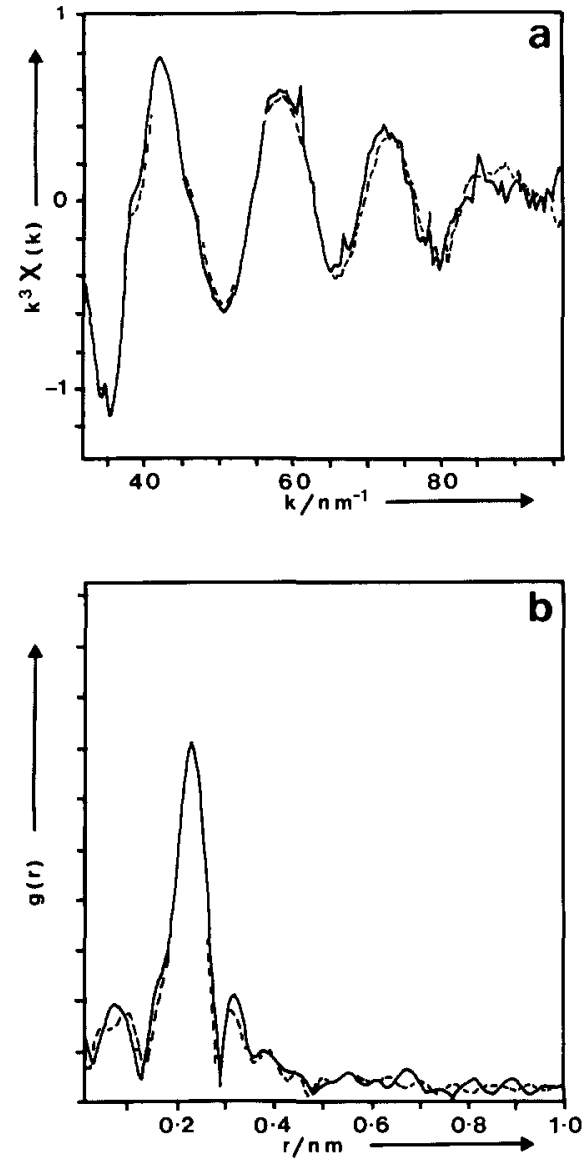

Fig. 3. (a) The EXAFS spectrum of sample T1 (compared to that of the ACP prepared at $\mathrm{pH} 10(---)$. (b) Moduli of the Fourier transforms of the spectra.

shown in fig. 3 and are compared to the EXAFS spectrum and modulus of the Fourier transform of the basic amorphous tricalcium phosphate [9]. The spectra and Fourier transforms appear very similar, showing short range order about the absorbing $\mathrm{Ca}^{2+}$ sites out to about $0.4 \mathrm{~nm}$. The EXAFS
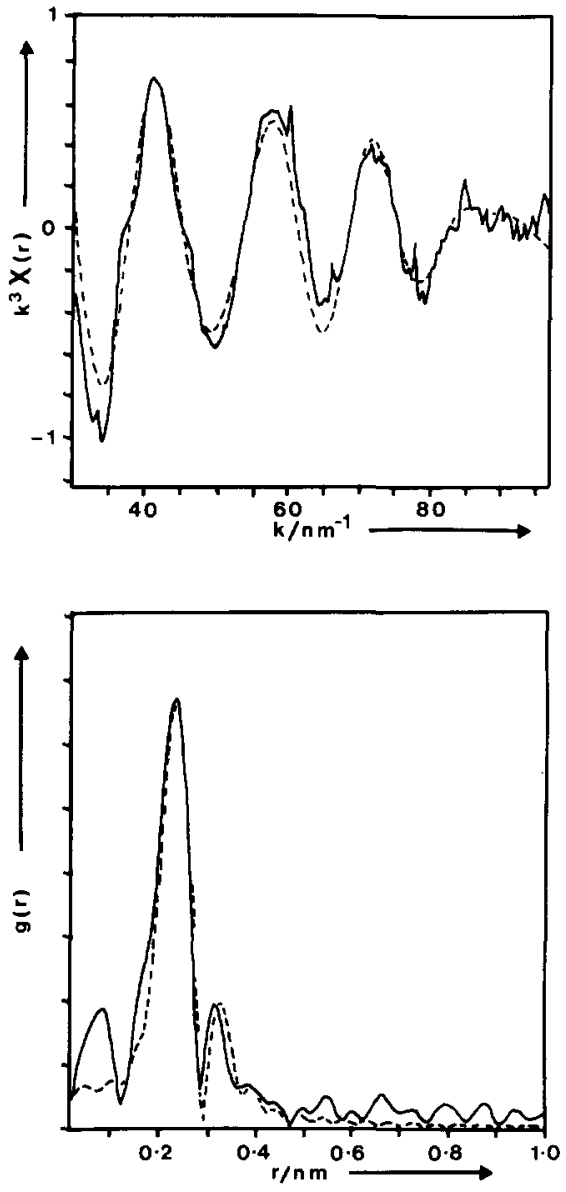

Fig. 4. Comparison of experimental ( $\longrightarrow$ ) and theoretical (- - -) EXAFS spectra for sample T1. The theoretical curve used the shell parameters in table 2 derived from the shell model of hydroxyapatite.

spectra of all the ACPs prepared at $\mathrm{pH} 7$ were found to be very similar.

When the hydroxyapatite model was used for curve fitting, as discussed elsewhere [9], the final

Table 2

Shell parameters derived from the models for hydroxyapatite and brushite that fit the EXAFS spectrum of sample T1

\begin{tabular}{|c|c|c|c|c|c|c|c|}
\hline \multicolumn{4}{|c|}{ Apatite model } & \multicolumn{4}{|c|}{ Brushite model } \\
\hline $\begin{array}{l}\text { Atom } \\
\text { type }\end{array}$ & $\begin{array}{l}\text { Occupation } \\
\text { number }\end{array}$ & $\begin{array}{l}\text { Radius } \\
\text { (nm) }\end{array}$ & $\begin{array}{l}\text { Debye-Waller } \\
\left(10^{-2} \mathrm{~nm}^{2}\right)\end{array}$ & $\begin{array}{l}\text { Atom } \\
\text { type }\end{array}$ & $\begin{array}{l}\text { Occupation } \\
\text { number }\end{array}$ & $\begin{array}{l}\text { Radius } \\
(\mathrm{nm})\end{array}$ & $\begin{array}{l}\text { Debye-Waller } \\
\left(10^{-2} \mathrm{~nm}^{2}\right)\end{array}$ \\
\hline$\overline{\mathrm{O}}$ & 5.4 & 0.236 & 0.016 & $\mathrm{O}$ & 8 & 0.237 & 0.028 \\
\hline $\mathrm{O}$ & 3.0 & 0.254 & 0.015 & & & & \\
\hline $\mathbf{P}$ & 2.4 & 0.308 & 0.025 & $\mathbf{P}$ & 2 & 0.304 & 0.020 \\
\hline
\end{tabular}



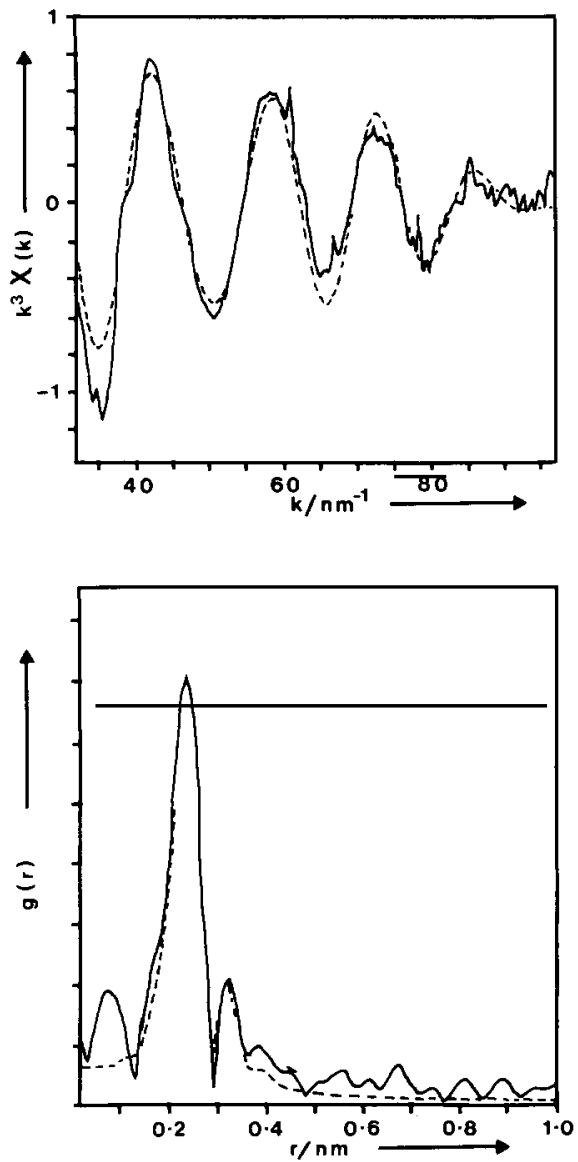

Fig. 5. Comparison of experimental (—) and theoretical ( - - -) EXAFS spectra for sample T1. The theoretical curve used the shell parameters in table 2 derived from the shell model of brushite.

refined parameters giving the closest agreement between theory and experiment (fig. 4) were very similar to those found for the basic ACP salt [9] and included only the three innermost shells. These parameters are listed in table 2, together with the final parameters obtained by refinement from the brushite model. In fitting the spectrum using the brushite model, only the first three shells were used, comprising the eight nearest neighbour oxygens and the two next nearest neighbour phosphorus atoms. These three shells alone were also able to account for all the reproducible structural features observed in the EXAFS spectrum and its Fourier transform (fig. 5). On refinement it was found that the more distant phosphorus atom, located $0.320 \mathrm{~nm}$ from calcium in crystalline brushite (from EXAFS) moves in closer to calcium resulting in two essentially equidistant phosphorus atoms at $0.302 \mathrm{~nm}$. It may be that when the constraints of the brushite lattice are removed the nearest neighbour phosphate groups can move to a new energy minimum in which calcium lies centrally between them. It is clear from table 2 that the shell models of both brushite and hydroxyapatite can be adapted to fit the spectrum of the ACP prepared at $\mathrm{pH} \mathrm{10,} \mathrm{where} \mathrm{most} \mathrm{of} \mathrm{the}$ phosphate is $\mathrm{PO}_{4}^{3-}$, and the ACPs prepared at $\mathrm{pH}$ 7 where an appreciable proportion of the phosphate groups are protonated. The recorded EXAFS spectra therefore do not readily distinguish between the different ACPs.

Since short range order alone is present in these amorphous calcium phosphates, no scattering contribution from cations is expected; the nearest cation to calcium is $0.39 \mathrm{~nm}$ away in brushite. Harries et al. reported that the substitution of calcium by magnesium in basic calcium phosphates produced no discernible changes in the EXAFS spectrum [9]. This is not to say, however, that $\mathrm{Mg}^{2+}$ does not alter the short range structure around its own binding sites. It therefore appears that whatever influence magnesium has in determining the nature of the calcium phosphate phase precipitated, it is not affecting the immediate environment of the calcium ions.

\subsection{Fourier transform infrared spectra}

The infrared spectrum of sample $\mathrm{H} 3$ is shown in fig. 6. The spectrum was also recorded as a nujol mull and the features due to the calcium phosphate were very similar. Sample H3 is typical of all the samples listed in table 1 with the exception that a sharp nitrate peak appears in sample $\mathrm{T} 1$ due to trapped $\mathrm{KNO}_{3}$ in the precipitate. Very similar spectra to $\mathrm{H} 3$ have been reported by Termine and Eanes [1] for a calcium phosphate sample prepared at $\mathrm{pH} 6.6$ in the absence of magnesium ions and by Wuthier et al. [13] for an amorphous calcium phosphate precipitated at $\mathrm{pH}$ 7.1 in the presence of magnesium ions. The spectrum in fig. 6 shows only the broad and relatively featureless bands typical of amorphous hydrated 


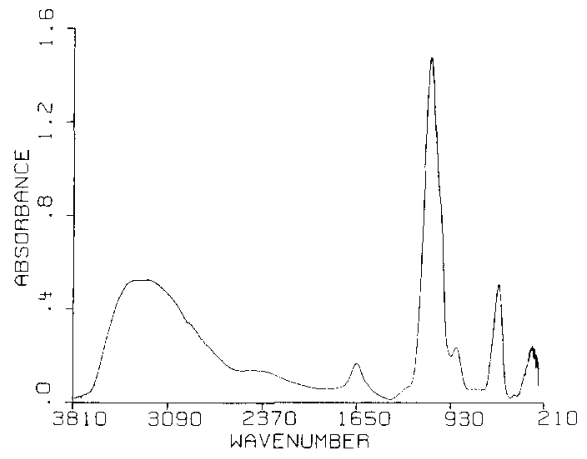

Fig. 6. Infrared spectrum of sample H3.

calcium phosphates, confirming the results of $\mathrm{X}$ ray powder diffraction and EXAFS spectroscopy. As is appropriate for such samples, interpretation of the spectrum will be discussed in terms of the internal vibrational modes of water and phosphate species in an aqueous environment [30,31]. The limited effects of site symmetry and factor group splitting of phosphate will be discussed in relation to the deconvolved spectrum where overlapping bands are more easily identified.

\subsubsection{Provisional assignments}

The principal feature of the spectrum of $\mathrm{H} 3$ is the very strong band at $1085 \mathrm{~cm}^{-1}$ with a shoulder at about $1010 \mathrm{~cm}^{-1}$. In this region the symmetric and degenerate asymmetric stretching modes of $\mathrm{HPO}_{4}^{2-}$ and $\mathrm{PO}_{4}^{3-}$ are expected. The strong and asymmetric broad band at around $3300 \mathrm{~cm}^{-1}$ is probably due to the $\mathrm{OH}$ stretching modes of water molecules and the $\mathrm{OH}$ stretch of $\mathrm{HPO}_{4}^{2-}$. A strong band at $555 \mathrm{~cm}^{-1}$ and a band of medium intensity at $290 \mathrm{~cm}^{-1}$ can be assigned to the $\mathrm{O}-\mathrm{P}-\mathrm{O}$ bending modes of $\mathrm{HPO}_{4}^{2-}$ and $\mathrm{PO}_{4}^{3-}$.

There is no clearly resolved band at about 1230 $\mathrm{cm}^{-1}$ corresponding to the $\mathrm{P}-\mathrm{O}-\mathrm{H}$ deformation but there is a broad shoulder of low intensity at about $1250 \mathrm{~cm}^{-1}$ which overlaps the phosphate stretching region. In octacalcium phosphate, shoulders at about 1280 and $1190 \mathrm{~cm}^{-1}$ have been assigned to a component of the $\mathrm{P}-\mathrm{O}-\mathrm{H}$ deformation though the latter was considered a possible asymmetric stretch of $\mathrm{HPO}_{4}^{2-}$ [32]. The most characteristic feature of the presence of $\mathrm{HPO}_{4}^{2-}$ species is however the broad band of medium intensity at about $890 \mathrm{~cm}^{-1}$ which is virtually absent from the spectrum of the basic amorphous calcium phosphate (fig. 8). The infrared spectrum of $\mathrm{H} 3$ and the other ACPs prepared at $\mathrm{pH} 7$ therefore provides a ready means of distinguishing it from basic aCPs.

\subsubsection{Fourier self-deconvolution of the phosphate stretching region}

The interpretation of the infrared spectrum of the amorphous phase in terms of the degenerate and non-degenerate modes of the $\mathrm{HPO}_{4}^{2-}$ and $\mathrm{PO}_{4}^{3-}$ ions in an aqueous environment assumes that the structure of the solid is sufficiently disordered to appear liquid-like. Local field effects may, however, lower the symmetry of phosphate sites, resulting in the partial or complete lifting of degeneracy and the occasional appearance of forbidden transitions. Fourier self-deconvolution was employed to enhance features that could be discerned in the recorded spectrum, particularly in the region $1300-700 \mathrm{~cm}^{-1}$ where the degenerate phosphate stretching modes are found.

In the undeconvolved spectrum of sample $\mathrm{H} 3$ the major broad band at about $1085 \mathrm{~cm}^{-1}$, has a shoulder at about $1005 \mathrm{~cm}^{-1}$. Close inspection of the major peak suggests additional features at 1250 and $950 \mathrm{~cm}^{-1}$ (fig. 7.) For deconvolution Lorentzian peak widths of 40,50 and $70 \mathrm{~cm}^{-1}$ were employed since no single choice of peak width brought out all the underlying features to best effect. Larger peak widths were found not to reveal any additional features and smaller peak widths enhanced the baseline ripples and noise and tended to introduce features not apparent in the original spectrum. Likewise, $K$ values of 2.0 , and 2.5 and 3.0 were found to be useful. The effects of spectral self-deconvolution in the phosphate stretching region are illustrated in fig. 7. With $K=2.0$ at all peak widths, the prominent shoulder at about $1005 \mathrm{~cm}^{-1}$ was resolved as well as the shoulders at about 950 and $1250 \mathrm{~cm}^{-1}$. With $K$ increased to 2.5 and all peak widths, a shoulder or peak at about $1045 \mathrm{~cm}^{-1}$ was also revealed and the peak at $890 \mathrm{~cm}^{-1}$ also showed some substructure. Further structuring of the main component at $1080 \mathrm{~cm}^{-1}$ is seen with $K=3.0$ but 


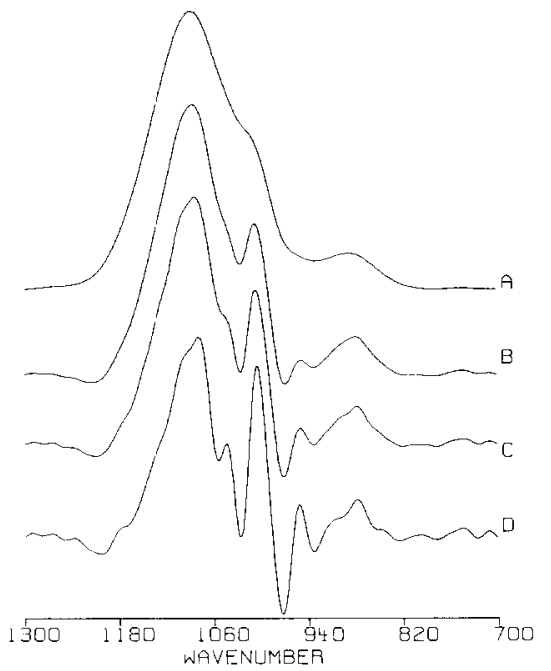

Fig. 7. Infrared spectrum of sample $\mathrm{H} 3$ in the phosphate stretching region (A) and after Fourier self-deconvolution (B-D) using peak widths $\left(\mathrm{cm}^{-1}\right)$ and $K$ values of, respectively, 40, $2.0(\mathrm{~B})$; 50, 2.5 (C); and 70, 3.0 (D).

the additional features are not apparent in the undeconvolved spectrum.

In general, very similar results were obtained on deconvolving each of the other sample spectra with the exceptions that sample $\mathrm{Tl}$ showed a less prominent very broad and weak shoulder at about $1250 \mathrm{~cm}^{-1}$ but the composite nature of the band at $890 \mathrm{~cm}^{-1}$ was more easily discerned, even without deconvolution. Clearly, the intrinsic widths of the absorption bands corresponding to the internal modes of the $\mathrm{PO}_{4}^{3-}$ and $\mathrm{HPO}_{4}^{2-}$ species are large and the local field effects are insufficient to lift the degeneracy of the asymmetric phosphate stretches. Nevertheless, the deconvolved spectrum provides a sensitive means of characterising and distinguishing between the amorphous calcium phosphates.

\subsubsection{Comparison with the amorphous tricalcium phosphate}

The infrared spectrum of sample $\mathrm{H} 3$ over the range $1300-700 \mathrm{~cm}^{-1}$ is compared to that of the amorphous tricalcium phosphate prepared at $\mathrm{pH}$ 10 in fig. 8. It is apparent that the major peak of $\mathrm{H} 3$ has its maximum absorbance at higher wavenumber and is broader than the peak in the other amorphous sample. Sample H3 absorbs more strongly from about $1150 \mathrm{~cm}^{-1}$ to the region of the shoulder at about $1250 \mathrm{~cm}^{-1}$ provisionally attributed to the $\mathrm{P}-\mathrm{O}-\mathrm{H}$ bending mode of $\mathrm{HPO}_{4}^{2-}$. A further difference is that the $\mathrm{O}-\mathrm{P}-\mathrm{O}$ bending mode at about $550 \mathrm{~cm}^{-1}$ occurs at a slightly lower wavenumber in the spectrum of the basic ACP compared to that of the more acidic ones (not shown).

The features which the deconvolved spectra of the two amorphous calcium phosphates have in common (fig. 8) are the peaks at about 1080, 1045, 1010 , and $950 \mathrm{~cm}^{-1}$. The degenerate asymmetric stretching mode of phosphate species in an aqueous environment occurs at about $1080 \mathrm{~cm}^{-1}$ and the peak at $1045 \mathrm{~cm}^{-1}$ is possibly due to the effects of site symmetry in partially lifting the degeneracy of these modes. The prominent shoulder in the spectra of the acidic ACPs, revealed by deconvolution as a band at about 1010 $\mathrm{cm}^{-1}$, may be due to the allowed symmetric stretch of the $\mathrm{HPO}_{4}^{2-}$ species and the shoulder at about $950 \mathrm{~cm}^{-1}$ may be assigned to the symmetric stretch of the $\mathrm{PO}_{4}^{3-}$ species when the effects of site asymmetry make the mode active in the infrared.

The most obvious difference between the acidic and basic ACPs is, however, the peak at about 890 $\mathrm{cm}^{-1}$ (fig. 8). An attempt was made to relate the area under this band to the $(\mathrm{H}-\mathrm{OH})$ content of the amorphous samples. To calibrate the relationship, samples of brushite and partly matured calcium phosphates derived from samples of type T1 were used. These showed a band of medium intensity at about $884 \mathrm{~cm}^{-1}$ due to the $\mathrm{P}-\mathrm{O}(\mathrm{H})$ stretch partly overlapping a broader band at about
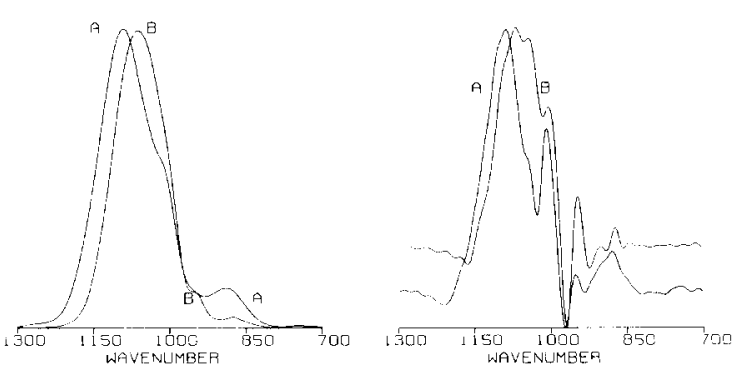

Fig. 8. Comparison of the infrared spectrum of sample H3 (A) with that of the ACP prepared at $\mathrm{pH} 10$ (B) in the phosphate stretching region before (left) and after (right) Fourier self-deconvolution using a peak width of $50 \mathrm{~cm}^{-1}$ and $\mathrm{K}$ value of 2.5 . 
$785 \mathrm{~cm}^{-1}$ due to a component of the $\mathrm{P}-\mathrm{O}-\mathrm{H}$ deformation. Using the Nicolet BLC routine a quadratic baseline was constructed to pass through the absorption minima at about 1900, 930 and 775 $\mathrm{cm}^{-1}$ and the area between 931 and $838 \mathrm{~cm}^{-1}$ was found. The areas were normalized by dividing by the weight of phosphorus in the $\mathrm{KBr}$ disks and a good linear relationship with $(\mathrm{H}-\mathrm{OH})$ resulted. After making a similar baseline correction to the spectra of the amorphous samples and normalization, the areas under the peak at about $890 \mathrm{~cm}^{-1}$ were found to be approximately twice as large as expected from their $(\mathrm{H}-\mathrm{OH})$ contents. It appears therefore that this feature in the spectra of the amorphous samples is not simply due to the $\mathrm{P}-\mathrm{O}(\mathrm{H})$ stretch but overlaps with some other resonance.

\subsection{Maturation of the amorphous calcium-mag- nesium phosphate}

Infrared spectroscopy and X-ray powder diffraction showed that all of the samples in table 1 matured to form brushite if left in contact with the aqueous solution but a detailed study of the maturation process was made for sample $\mathrm{T} 1$ only. The chemical composition of the precipitate remained constant for about $7 \mathrm{~h}$ until the solution $\mathrm{pH}$ began to rise, coinciding with the appearance of plate-like crystals. No morphological change in these samples was detected by electron microscopy prior to the appearance of the crystals. They seem to form in close contact with the amorphous material suggesting that the later acts as a template for heterogeneous nucleation (fig. $2 b)$. When a field containing only well developed plate-like crystals was examined by X-ray microanalysis, a $\mathrm{Ca} / \mathrm{P}$ ratio of 1.01 was obtained with no magnesium or potassium present, indicating that at least the larger plates are a pure dicalcium phosphate. Infrared spectroscopy and X-ray powder diffraction demonstrated that brushite was present in only those samples in which plate-like crystals could also be detected. After $39 \mathrm{~h}$ of maturation, only the plate-like crystals could be seen (fig. 2c). However, the chemical analysis indicated that even after $44 \mathrm{~h}$ there was still some magnesium in the samples and hence that conversion to brushite was incomplete.

The change in the content of potassium with time was positively correlated with the loss of nitrate $(r=0.985)$ and had unit slope. This is consistent with the finding by X-ray diffraction and electron microscopy of a separate phase of $\mathrm{KNO}_{3}$ crystals which therefore are present to a decreasing extent in the recovered precipitate as it ages. Precipitate magnesium content also decreased with maturation time and was negatively correlated with $(\mathrm{H}-\mathrm{OH})$. However, the relationship was curvilinear, only attaining a slope of -2 after several hours, indicating that maturation does not involve a simple substitution of $\mathrm{Mg}^{2+}$ by $2 \mathrm{H}^{+}$ in the amorphous material.

The infrared spectra of the partly matured samples were recorded and the proportion of brushite determined by spectral subtraction. In all cases, the proportion of brushite was appreciably less than the fraction of protonated phosphate groups, as determined chemically. Moreover, when the spectra of the remaining non-brushite material are compared (fig. 9), they show a gradual progression from an initial amorphous spectrum to spectra that themselves become increasingly more brushite-like. The conclusion is that the amorphous phase is replaced by plate-like crystals of brushite nucleating on the surface of the amorphous phase. The small proportion of material with an intermediate structure is possibly formed at the interface between the amorphous phase and the plates of brushite.

The mechanism of the transformation is not clearly established by the present results. Various arguments indicate that it proceeds by a solutionmediated transformation in which brushite forms heterogeneously while the amorphous phase dissolves. Thus, the electron micrographs show the characteristic plate-like morphology of brushite crystals after $7 \mathrm{~h}$ of maturation but no change in the morphology of the amorphous phase is seen beforehand, as might be expected if the transformation were a solid to solid transition in which the precursor phase does not dissolve. The initial amorphous phase probably nucleates during the addition of the $\mathrm{KOH}$ solution under conditions far from equilibrium and hence can be expected to 


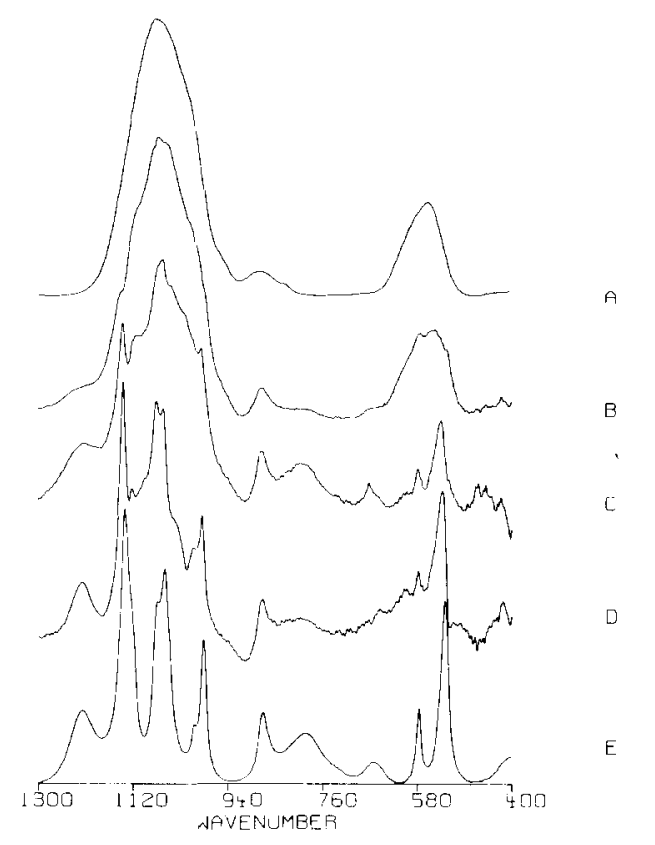

Fig. 9. Infrared spectra of the initial and partly matured samples of sample T1 after subtraction of the spectrum of brushite for mole fractions of brushite of 0 (A); 0.49 (B); 0.60 (C) and 0.65 (D). Spectrum $E$ is of brushite.

dissolve once a more thermodynamically stable phase is formed $[4,27,28]$ under more moderate solution conditions. The amorphous calcium phosphates were seen to dissolve rapidly as a result of even small changes in solution composition.

The final argument in favour of a solution mediated transformation is less direct. With the $\mathrm{Mg} / \mathrm{Ca}$ ratios of the solid ACPs in the range of approximately $0.2-0.3$, transformation to HAP is unlikely [4]. Moreover, in the absence of magnesium ions, OCP is the expected to form at $\mathrm{pH} 7$ $[1,16,29]$. In seeded growth experiments, however, it has been shown that magnesium ions strongly retard the growth of OCP whereas the growth of brushite is hardly affected [33,34]. Thus, while OCP is the more thermodynamically stable phase at $\mathrm{pH} \mathrm{7,} \mathrm{brushite} \mathrm{is} \mathrm{formed} \mathrm{due} \mathrm{to} \mathrm{selective} \mathrm{inhibi-}$ tion of other crystalline phases. This suggested that the maturation of the ACP in our experiment proceeds by a similar mechanism in which magnesium ions exert the same inhibitory function, i.e. inhibition of a solution mediated conversion to
OCP but no inhibition of the growth of the brushite crystals.

\section{Conclusions}

(1) Amorphous calcium-magnesium phosphates have been prepared at $\mathrm{pH} 7$ in which up to about half the phosphate groups are protonated. The degree of protonation increases linearly with the magnesium content of samples and with the ratio of the magnesium to calcium ion concentrations in the supernatant.

(2) The EXAFS spectra of the samples can be fitted using virtually the same shell model as was used to fit the spectrum of an amorphous tricalcium phosphate prepared at $\mathrm{pH} 10$, indicating similar short range structure near the calcium ions in the two types of samples. A shell model based on the X-ray crystal structure of brushite can also be adapted to fit the EXAFS spectra.

(3) The calcium-magnesium phosphates can be distinguished from the basic amorphous tricalcium phosphate by their infrared spectra. In particular, a band of medium intensity at about $890 \mathrm{~cm}^{-1}$ and a shoulder at about $1250 \mathrm{~cm}^{-1}$ appear to be characteristic features of acid calcium phosphates. In addition the main phosphate stretching peak is broader and its maximum intensity is at a higher wavenumber in the acidic calcium phosphates. Fourier self-deconvolution of the phosphate stretching region reveals more clearly the characteristic differences in the shape of this band in the different amorphous calcium phosphates.

(4) The amorphous calcium-magnesium phosphate matures, in the presence of solutions containing $\mathrm{Mg}^{2+}$, to form brushite. The mechanism of transformation probably involves the growth of brushite from solution at the expense of the amorphous phase, rather than a direct solid to solid transformation.

\section{Acknowledgements}

We thank Elaine Little for assistance in the preparation of samples $\mathrm{H} 1-\mathrm{H} 3$ and in the chemical analyses and J. Pieters for help with electron 
microscopy. The Director and staff of the SERC Daresbury Laboratory are thanked for the provision of facilities for the EXAFS work. Financial support in the UK was provided by DAFS, AFRC and SERC. In The Netherlands, financial support was received from NIZO.

\section{References}

[1] J.D. Termine and E.D. Eanes, Calcif. Tissue Res. 10 (1972) 171.

[2] J.L. Meyer and E.D. Eanes, Calcif. Tissue Res. 25 (1978) 59.

[3] J.L. Meyer, Calcif. Tissue Intern. 27 (1979) 153.

[4] A.L. Boskey and A.S. Posner, J. Phys. Chem. 77 (1973) 2313.

[5] P.-T. Cheng and K.P.H. Pritzker, Calcif. Tissue Intern. 35 (1983) 596.

[6] F. Abbona, H.E. Lundager Madsen and R. Boistelle, J. Crystal Growth 74 (1986) 581.

[7] F. Betts and A.S. Posner, Mater. Res. Bull. 9 (1974) 353.

[8] F. Betts and A.S. Posner, Trans. Am. Cryst. Assoc. 10 (1974) 73 .

[9] J.E. Harries, D.W.L. Hukins, C. Holt and S.S. Hasnain, J. Crystal Growth 84 (1987) 563.

[10] M.D. Francis and N.C. Webb, Calcif. Tissue Res. 6 (1971) 335.

[11] C. Holt, S.S. Hasnain and D.W.L. Hukins, Biochim. Biophys. Acta 719 (1982) 299.

[12] T.C.A. McGann, R.D. Kearney, W. Buchheim, A.S. Posner, F. Betts and N.C. Blumenthal, Calcif. Tissue Intern. 35 (1983) 821.

[13] R.E. Wuthier, G.S. Rise, J.E.B. Wallace, Jr., R.L. Weaver, R.Z. Legeros and E.D. Eanes, Calcif. Tissue Intern. 37 (1985) 401.

[14] C. Holt, D.G. Dalgleish and R. Jenness, Anal. Biochem. $113(1981) 154$.
[15] A.C. Vermeulen, J.W. Geus, R.J. Stol and P.L. de Bruyn, J. Colloid Interface Sci. 51 (1975) 449.

[16] M.J.M. van Kemenade and P.L. de Bruyn, J. Colloid Interface Sci. 118 (1987) 564.

[18] G.T. Pyne and J.J. Ryan, J. Dairy Res. 17 (1950) 200.

[19] A.J. Cox, J.E. Harries, D.W.L. Hukins, A.P. Kennedy and T.M. Sutton, Brit. J. Urol. 59 (1987) 159.

[20] J.E. Harries, J.C. Irlam, C. Holt, S.S. Hasnain and D.W.L. Hukins, Mater. Res. Bull. 22 (1987) 1151.

[21] P. Eisenberger and B.M. Kincaid, Science 200 (1978) 1441.

[22] P.A. Lee, P.H. Citrin, P. Eisenberger and B.M. Kincaid, Rev. Mod. Phys. 53 (1981) 769.

[23] S.J. Gurman, J. Mater. Sci. 17 (1982) 1541.

[24] S.J. Gurman, N. Binsted and I. Ross, J. Phys. C (Solid State Phys.) 17 (1984) 143.

[25] J.E. Harries, D.W.L. Hukins and S.S. Hasnain, J. Phys. C (Solid State Phys.) 19 (1986) 6859.

[26] J.K. Kauppinen, D.J. Moffat, H.H. Mantsch and D.G. Cameron, Anal. Chem. 53 (1981) 1454.

[27] N.C. Blumenthal and A.S. Posner, Calcif. Tissue Res. 13 (1973) 235.

[28] A.S. Posner and F. Betts, Accounts Chem. Res. 8 (1975) 273.

[29] T.P.L. Feenstra and P.L. de Bruyn, J. Phys. Chem. 83 (1979) 475

[30] E.E. Berry and C.B. Baddiel, Spectrochim. Acta 23A (1967) 2089.

[31] A.C. Chapman and L.E. Thirlwell, Spectrochim. Acta 20 (1964) 937.

[32] B.O. Fowler, E.C. Moreno and W.E. Brown, Arch. Oral Biol. 11 (1966) 477.

[33] M.H. Salimi, J.C. Heughebaert and G.H. Nancollas, Langmuir 1 (1985) 119.

[34] M.J.M. van Kemenade and P.L. de Bruyn, J. Colloid Interface Sci., in press. 